\title{
A PULVERIZAÇÃo AÉREA DE AGROTÓXICOS NO BRASIL: CENÁRIO ATUAL E DESAFIOS
}

Aerial spraying of pesticides in Brazil: current scenario and challenges

${ }^{1}$ Centro de Ensino Superior de Santa Catarina. Florianópolis/SC, Brasil.

Correspondência: Maria Leonor Paes Cavalcanti Ferreira. E-mail: marialeonorf@hotmail.com.

Recebido em: 19/12/2013. Revisado em: 30/06/2014. Aprovado em: 25/07/2014. 


\section{RESUMO}

Este artigo objetiva discutir os riscos decorrentes da pulverização aérea de agrotóxicos, fazendo uma análise, ainda, de considerações sobre a nomenclatura desse tipo de produto e de sua contribuição para a configuração e o agravamento de uma sociedade de risco. Apresenta a legislação brasileira pertinente, propondo, em decorrência do princípio da prevenção, a necessidade urgente de proibir a modalidade de aplicação de agrotóxicos por meio de pulverização aérea.

\section{Palavras-chave}

Agrotóxicos; Legislação; Pulverização Aérea.

\section{ABSTRACT}

This article aims at discussing the risks of aerial spraying of pesticides, analyzing the concerns about the designation of these products, and their contribution to establishment and aggravating a society at risk. This article presents relevant Brazilian legislation, and proposes, as a result of the precautionary principle, the urgent need to ban pesticide application via aerial spraying.

\section{Keywords}

Aerial Spraying; Legislation; Pesticides. 


\section{Introdução}

O Brasil ocupa atualmente uma posição de destaque quando o assunto é a produção agrícola. O modelo agrícola adotado no País, entretanto, está fortemente vinculado ao uso de agrotóxicos, considerando-se que a agricultura brasileira centra-se em um modelo de desenvolvimento voltado a ganhos de produtividade.

Nesse cenário, os impactos para o meio ambiente e para a saúde humana têm sido negligenciados, e a contaminação dos recursos ambientais passa a ser uma realidade que ameaça a qualidade de vida das presentes e futuras gerações.

Uma das formas de utilização de agrotóxicos ainda em vigor no Brasil, apesar dos enormes impactos para o meio ambiente e para a saúde humana, consiste na aplicação aérea desses produtos.

Neste artigo, pretende-se analisar a legislação brasileira sobre o tema, propondo-se algumas ideias necessárias para se proporcionar uma agricultura ecologicamente mais equilibrada e com menores riscos à saúde humana. Para alcançar tal objetivo, inicialmente, discutiram-se alguns aspectos relacionados aos agrotóxicos, entre eles a questão da nomenclatura e os riscos decorrentes do uso desses químicos. Em seguida, procurou-se aprofundar a pesquisa sobre a contribuição dessas substâncias para a configuração de uma sociedade de risco. Finalmente, procurou-se examinar a regulação da modalidade de aplicação por pulverização aérea de agrotóxicos, a partir de uma análise crítica acerca do cenário atual e dos desafios pertinentes.

\section{Agrotóxicos: considerações sobre a nomenclatura}

Os agrotóxicos, inicialmente considerados um símbolo do progresso agrícola, são produtos da ciência utilizados com o objetivo de se garantir o aumento de produtividade através do controle de pragas e estão entre os principais instrumentos do atual modelo de desenvolvimento da agricultura brasileira, centrado em ganhos de produtividade ${ }^{1}$.

Estima-se que as pragas agrícolas e outros patógenos destroem cerca de $10 \%$ a $40 \%$ da produção agrícola bruta no mundo ${ }^{2}$. Os danos ocasionados por esses agentes podem resultar na elevação de preço dos alimentos e no empobrecimento de sua qualidade, bem como no aumento da dependência de produtos importados ${ }^{3}$.

\footnotetext{
${ }^{1}$ INSTITUTO BRASILEIRO DE GEOGRAFIA E ESTATÍSTICA (IBGE). Indicadores de desenvolvimento Sustentável. Brasil 2010. Disponível em: <http://www.ibge.gov.br/home/geociencias/recursosnaturais/ids/ids2010. pdf>. Acesso em: 06 set. 2010.

2PRETTY, Jules; GUIJT, Irene; SCOONES, Ian; THOMPSON, John. Regenerating Agroecology of low-external input and community-based development. In: KIRKBY, John; O'KEEFE, Phil; TIMBERLAKE, Lloyd (Eds.). The earthscan reader in sustainable development. UK, 1999. p. 132.

${ }^{3}$ GODOY, R. C. B. de; OLIVEIRA, M. I. de. Agrotóxicos no Brasil: processo de registro, riscos à saúde e programas de monitoramento. Cruz das Almas: Embrapa Mandioca e Fruticultura Tropical, 2004. p. 30. (Embrapa e Mandioca e Fruticultura Tropical. Documentos, 134). Disponível em: <http://www.cnpmf. embrapa.br/ publicacoes/folder/folder_nim_2006.pdf>. Acesso em: 02 out. 2011.
} 
É esse potencial de dano que tem dirigido a procura por pesticidas e resultado em seu uso generalizado 4 .

A partir da década de 1960, em especial com a Revolução Verde, houve a massificação da utilização dos pesticidas. Essa revolução consistiu na adoção de práticas agrícolas baseadas no uso intensivo de insumos químicos e instrumentos mecânicos pelos países menos desenvolvidos ${ }^{5}$. Com isso, os agricultores intensificaram os recursos para produzir mais a partir da mesma quantidade de terra e expandir a produção para áreas não cultivadas. A condição para a Revolução Verde se concretizar foi a criação pelos cientistas agrícolas de novas variedades de cerais básicos que: (a) amadureciam rapidamente, permitindo que duas ou três colheitas fossem cultivadas a cada ano; (b) eram insensíveis à duração do dia, podendo ser estendidas a agricultores em uma ampla gama de latitudes; (c) eram produtoras de mais grãos à custa de palha. A distribuição dessas variedades modernas (modern varities, MD) ocorreu juntamente com insumos de alto custo, incluindo fertilizantes inorgânicos, máquinas e pesticidas 6 .

Mais recentemente, a indústria da biotecnologia também tem contribuído para a perpetuação do uso dos agrotóxicos. Embora existisse o mito de que essa indústria inauguraria um período de agricultura sem pesticidas, a maior parte das pesquisas e inovações da biotecnologia agrícola foi feita por multinacionais de produtos químicos como a Ciba Geigy, a ICI, a Monsanto e a Hoechst. Assim, ao contrário das promessas, as lavouras transgênicas levaram a um considerável aumento do uso dos agrotóxicos, pois as empresas que desenvolvem e vendem as sementes transgênicas são as mesmas que fabricam e vendem agrotóxicos ${ }^{7}$.

Os pesticidas podem ter um importante papel ao auxiliarem no cumprimento das exigências de qualidade impostas pelos setores da saúde em relação aos alimentos, permitindo, assim, o comércio internacional de produtos agrícolas. Além disso, esses produtos têm sido utilizados com o objetivo de minimizar a necessidade de mão de obra ${ }^{8}$.

De acordo com Déoux ${ }^{9}$, os pesticidas são produtos utilizados para proteger as culturas dos insetos e parasitas, das ervas daninhas e de outros agentes de doenças vegetais. A respeito do tema, convém lembrar que uma das formas de classificar

\footnotetext{
${ }^{4}$ PRETTY, Jules; GUIJT, Irene; SCOONES, Ian; THOMPSON, John. op. cit., p. 132

${ }^{5}$ ALBERGONI, Leide; PELAEZ, Victor. Da Revolução Verde à agrobiotecnologia: ruptura ou continuidade de paradigmas? Revista de Economia, Curitiba, v. 33, n. 1, p. 39, jan./jun. 200

${ }^{6}$ PRETTY, Jules; GUIJT, Irene; SCOONES, Ian; THOMPSON, John. op. cit., p. 126.

${ }^{7}$ LONDRES, Flávia. Agrotóxicos no Brasil: um guia para ação em defesa da vida. Rio de Janeiro: AS-PTA - Assessoria e Serviços a Projetos em Agricultura Alternativa, 2011. p. 69.

${ }^{8}$ COMISSÃO DAS COMUNIDADES EUROPEIAS. Comunicação da Comissão ao Conselho, ao Parlamento Europeu e ao Comitê Econômico e Social. Para uma estratégia temática da utilização sustentável dos Pesticidas. Bruxelas, 1.7.2002. COM (2002) 349 final. p. 12. Disponível em: <http://eur-lex.europa.eu/LexUriServ/ site/pt/com/2002/com2002_0349pt01.pdf>. Acesso em: 10 maio 2011.

${ }^{9}$ DÉOUX, Suzanne e Pierre. Ecologia é a saúde. Lisboa: Instituto Piaget, [s.d.]. p. 279.
} 
os agrotóxicos leva em consideração sua ação ou finalidade de uso, a ser definida pelo organismo-alvo. Assim sendo, algumas das classes de uso são: (a) inseticidas: quando controlam insetos, larvas e formigas; (b) fungicidas: quando controlam fungos; (c) herbicidas: quando controlam plantas; (d) acaricidas: quando controlam ácaros; (e) rodenticidas: quando controlam roedores; (f) nematicidas: quando controlam nematoides; e (g) molusquicidas: quando combatem moluscos, a exemplo do caramujo da esquistossomose ${ }^{10}$.

A legislação brasileira também conceitua esses produtos. De acordo com o artigo $2^{\circ}$, da Lei n. $7.802 / 1989^{11}$, são agrotóxicos:

a) os produtos e os agentes de processos físicos, químicos ou biológicos, destinados ao uso nos setores de produção, no armazenamento e beneficiamento de produtos agrícolas, nas pastagens, na proteção de florestas, nativas ou implantadas, e de outros ecossistemas e também de ambientes urbanos, hídricos e industriais, cuja finalidade seja alterar a composição da flora ou da fauna, a fim de preservá-las da ação danosa de seres vivos considerados nocivos; b) substâncias e produtos, empregados como desfolhantes, dessecantes, estimuladores e inibidores de crescimento; II - componentes: os princípios ativos, os produtos técnicos, suas matérias-primas, os ingredientes inertes e aditivos usados na fabricação de agrotóxicos e afins.

Conforme se depreende de seu conceito legal, os agrotóxicos são substâncias com um potencial inerente de controlar efeitos perigosos ou indesejados de outros organismos e podem ser utilizados na agricultura e em outros setores - por exemplo, na saúde pública - para controlar vetores de doenças humanas.

Assim, verifica-se que, atualmente no Brasil, a expressão utilizada na legislação em vigor para designar os pesticidas é “agrotóxico". A Lei n. 7.802/1978 reconheceu a periculosidade de tais produtos ao determinar inclusive, em seu artigo $8^{\circ}$, que a propaganda comercial de agrotóxicos, componentes e afins, em qualquer meio de comunicação, obrigatoriamente conterá "clara advertência sobre os riscos do produto à saúde dos homens, animais e ao meio ambiente".

Entretanto, deve-se recordar que, apesar dos riscos dessas substâncias químicas e de o conceito legal já consagrado ser o termo "agrotóxico", a expressão "defensivos agrícolas" ainda é bastante propagada pela indústria de pesticidas. Para

\footnotetext{
${ }^{10}$ ALMEIDA, Pedro José de. Intoxicação por agrotóxicos. São Paulo: Organização Andrei Ed., 2002. p. 28.

${ }^{11}$ BRASIL. Lei n. 7.802, de 11 de julho de 1989. Dispõe sobre a pesquisa, a experimentação, a produção, a embalagem e rotulagem, o transporte, o armazenamento, a comercialização, a propaganda comercial, a utilização, a importação, a exportação, o destino final dos resíduos e embalagens, o registro, a classificação, o controle, a inspeção e a fiscalização de agrotóxicos, seus componentes e afins, e dá outras providências. Disponível em: < http://www.planalto.gov.br/ccivil_03/leis/I7802.htm>. Acesso em: 06 mar. 2015.
} 
se ter ideia do grande uso dessa nomenclatura, basta consultar os sites a seguir elencados: <http://www.andef.com.br> e <http://www.monsanto.com.br >. Nodari, ao tratar do tema, alerta que políticos e técnicos dos governos federal, estadual e municipal também utilizam essa expressão. $\mathrm{O}$ autor assinala que "o mais intrigante é que até em universidades esse termo é utilizado" 12 .

Sob o nome neutro de "defensivos agrícolas", os agrotóxicos foram festejados como instrumentos essenciais para combater a fome, quando se sabe que esse problema não resulta da inadequada forma de produção dos alimentos, e sim de fatores econômicos, políticos e sociais que afetam a distribuição e o uso dos alimentos $^{13}$. Não por outra razão, o termo "defensivo agrícola" foi substituído pelo termo técnico "agrotóxico", mais condizente com os riscos dos referidos produtos. Essa nova denominação representa uma vitória do movimento ambientalista e da agricultura alternativa contra toda a pressão da indústria pela adoção do suave "defensivo agrícola"14.

Em Portugal, assim como ocorreu no Brasil, outros termos também foram utilizados para disfarçar os riscos desses produtos. Amaro afirma que surgiram, a partir do fim da década de 1980, numerosas alternativas para o uso da expressão "pesticida" - agroquímico, fitofármaco e produto de plantação de plantas (ppp) -, tendo sido privilegiadas outras designações menos usadas, como produto fitofarmacêutico, produto fitossanitário e produto antiparasitário. Nesse país, em junho de 2005, teve-se conhecimento de outra inovação: “agente de protecção de plantas", termo usado no documento intitulado Boletim da Ordem dos Engenheiros ${ }^{15}$.

Essas designações criadas objetivam mascarar a periculosidade das substâncias ora em exame. Trata-se de uma forma de ocultar os riscos, configurando-se um exemplo de mecanismo da "irresponsabilidade organizada"16. Esse fenômeno engloba um conjunto de mecanismos culturais e institucionais pelos quais as elites políticas e econômicas encobrem efetivamente as origens e consequências dos riscos e dos perigos catastróficos da recente industrialização ${ }^{17}$.

No caso dos agrotóxicos, fala-se, inclusive, na adoção de um tabu, isto é, a proibição do termo "pesticida”, o qual foi adotado não apenas pela indústria de pesticida, mas também por entidades internacionais, como a Organização Europeia

\footnotetext{
${ }^{12}$ NODARI, Rubens Onofre. Risco à saúde dos seres vivos advindo dos agrotóxicos - ênfase nos herbicidas. In: ARAGAO, Alexandra. LEITE, José Rubens Morato; FERREIRA, Jovino dos Santos Ferreira; FERREIRA, Maria Leonor Paes Cavalcanti. Agrotóxicos: a nossa saúde e o meio ambiente em questão - aspectos técnicos, jurídicos e éticos. Florianópolis: Funjab, 2012. p. 112.

${ }^{13}$ LUCCHESI, Geraldo. Agrotóxicos: a construção da legislação. Estudo, set. 2005. p. 3. Disponível em: <http://bd.camara.gov.br/bd/bitstream/handle/bdcamara/2227/agrotoxicos_construcao_lucchese. pdf?sequence=1>. Acesso em: 28 nov. 2011.

${ }^{14}$ LONDRES, Flávia. op. cit., p. 101.

${ }^{15}$ AMARO, Pedro. A política de redução dos riscos dos pesticidas em Portugal. Lisboa: ISA/PRESS, 2007. p. 107.

${ }^{16}$ BECK, Ulrich. Ecological politics in an age of risk. Trad. Amos Weisz. Cambridge: Polity, 1995. p. 55.

${ }^{17}$ GOLDBLATT, David. Teoria social e ambiente. Lisboa: Instituto Piaget, 1996. p. 241.
} 
de Proteção das Plantas e a própria Comunidade Europeia, e pelas autoridades fitossanitárias de alguns países, como Portugal ${ }^{18}$.

Feitas essas considerações acerca da nomenclatura desses produtos, passa-se no próximo item à análise dos riscos para o meio ambiente e para a saúde humana decorrentes da utilização desses químicos.

\section{Riscos para a saúde humana e para o meio ambiente decorrentes dos agrotóxicos}

Apesar dos alegados benefícios trazidos pelos agrotóxicos em termos de produtividade agrícola e, consequentemente, em termos econômicos, já não é novidade que esses produtos são perigosos para a saúde humana e o para o meio ambiente. Duas particularidades, entretanto, devem ser acentuadas quando se examinam os efeitos adversos desses produtos: os efeitos inter-relacionados - persistência dos resíduos no ambiente e nos alimentos - e os danos para a saúde, os quais são geralmente insidiosos e aparecem depois de um longo tempo ${ }^{19}$. Nesse sentido, recorde-se, por exemplo, o caso da atrazina, herbicida proibido na Alemanha desde 1991 cujos metabólitos ainda podem ser encontrados no meio ambiente, depois de todos esses anos. A persistência do referido herbicida no ambiente gera uma grande preocupação, em virtude do potencial cancerígeno e endócrino da atividade desse produto químico ${ }^{20}$.

Com relação particularmente aos efeitos adversos dos agrotóxicos, diversos trabalhos científicos já relataram a necessidade de tais substâncias serem utilizadas com cautela. Já em 1991, Pimentel apresentava estudo demonstrando que menos de $0,1 \%$ dos pesticidas aplicados nas culturas atingem as pragas-alvo e que, portanto, uma grande quantidade desses produtos é perdida durante o processo de aplicação - causando efeitos adversos para a saúde humana e para a biota benéfica, e contaminando o solo, a água e a atmosfera do ecossistema. O autor exemplifica tal assertiva, destacando que a deriva decorrente da aplicação aérea de agrotóxicos já atingiu uma distância de 32 quilômetros da área-alvo ${ }^{21}$.

Recentemente, a Empresa Brasileira de Pesquisa Agropecuária (Embrapa) apresentou estudos que comprovam a alta periculosidade da pulverização aérea. Segundo a empresa, normalmente ocorre uma "deriva técnica", de maneira que os atuais equipamentos de pulverização - mesmo com calibração, temperatura e ventos

\footnotetext{
${ }^{18}$ AMARO, Pedro. op. cit., p. 107.

${ }^{19}$ THRUPP, Lori Ann. Inappropriate incentives for pesticide use: agricultural credit requirements in developing countries. Agriculture and Human Values, v. 7, n. 3/4, p. 62, 1990.

${ }^{20}$ JABLONOWSKI, Nicolai Davi; SCHAFFER, Andreas; BUREAUL, PETER. Still present after all these year: persistence plus potential toxicity raise questions about the use of atrazine. Environmental Science and Pollution Research International, v. 18, n. 2, p. 328, Feb. 2011.

${ }^{21}$ PIMENTEL, David. Amounts of pesticides reaching target pests: environmental impacts and ethics. Journal of Agricultural and Environmental Ethics, v. 8, n. 1, p. 25, 1995.
} 
ideais - deixam 32\% dos agrotóxicos pulverizados retidos nas plantas; outros 49\% vão para o solo e $19 \%$ vão pelo ar para outras áreas circunvizinhas da aplicação ${ }^{22}$. A problemática envolvendo a pulverização aérea é razão não apenas de conflitos judiciais e de discussões acerca da necessidade de alterações na legislação brasileira, mas também de conflitos entre diferentes países.

Nesse sentido, há o exemplo do caso envolvendo o Equador e a Colômbia. Trata-se de demanda interposta pelo Equador em face da Colômbia, em virtude de alegada pulverização aérea de herbicidas realizada pela Colômbia na região de fronteira, causando danos à população equatoriana, bem como ao meio ambiente. $\mathrm{O}$ caso ainda se encontra pendente de julgamento, lembrando que o Equador opõe-se à exportação e ao consumo de drogas ilícitas, mas salientou que as questões levadas à Corte referem-se exclusivamente aos métodos e lugares escolhidos pela Colômbia para suas atividades de erradicação das plantações ilícitas de folhas de coca e papoula e aos efeitos prejudiciais dessas atividades no Equador ${ }^{23}$.

Além desse caso, convém registrar também que chegou para análise do Tribunal Centro-Americano de Água um conflito oriundo da pulverização aérea de agrotóxicos na cultura de banana na Província de Limón, localizada na Costa Rica. Quando da análise do caso, julgado em 2004, o tribunal em questão recomendou que a indústria bananeira suspendesse no longo prazo a pulverização aérea de agrotóxicos, insistindo em investigações e projetos que alterassem os métodos agrícolas ${ }^{24}$.

Além dos danos oriundos da pulverização aérea de agrotóxicos, deve-se mencionar que as pragas agrícolas possuem capacidade de desenvolver resistência aos agrotóxicos aplicados, que, dessa forma, perdem gradativamente sua eficácia, levando os agricultores a aumentar as doses aplicadas e/ou recorrer a novos produtos. O desequilíbrio ambiental ocasionado por esses produtos também leva ao surgimento de novas pragas e, assim, insetos ou plantas que antes não provocavam danos às lavouras passam a se comportar como invasoras e a atacar as plantações ${ }^{25}$. A respeito do tema, Nodari ensina que, embora seja justificado que agrotóxicos sejam utilizados para combater pragas ou doenças em plantas e animais, o que se

\footnotetext{
${ }^{22} \mathrm{CHAIM}$, Aldemir. Tecnologia de aplicação de agrotóxicos: fatores que afetam a eficiência e o impacto ambiental. In: SILVA, Célia Maria Maganhotto de Souza; FAY, Elisabeth Francisconi (Orgs.). Agrotóxicos \& ambiente. Brasília: Embrapa; 2004. p. 317.

${ }^{23}$ CORTE INTERNACIONAL DE JUSTIÇA. Letter from the ambassador of Ecuador (appointede) to the kingdom of the netherlands to the registrar of the International Court of Justice. The Hague, 31 Mar. 2008. p. 6. Disponivel em: <http://www.icj-cij.org/docket/files/138/14474.pdf\#view=FitH\&pagemode=none\&search =\%22herbicides\%22>. Acesso em: 29 nov. 2012.

${ }^{24}$ TRIBUNAL CENTROAMERICANO DEL AGUA. Caso: Fumigación aérea en finca Carrandi, Matina, Província de Limón. Marco Machore versus Standard Fruit Company, Ministerio de Obras Públicas y Transportes; Dirección General de Aviación Civil; Ministerio da Agricultura y Ganadería. Veredictos Segunda Audiencia Pública Llevada a cabo del 15 a 19 de marzo de 2004. San José, Costa Rica. p. 1. Disponível em: <http://tragua. com/wp-content/uploads/2012/04/veredicto_finca_carrandi.pdf>. Acesso em: 04 abr. 2013.

${ }^{25}$ LONDRES, Flávia. op. cit., p. 21.
} 
verificou foi a evolução da resistência em mais de centenas de espécies de insetos, fungos, bactérias e plantas aos agrotóxicos ${ }^{26}$.

No que se refere especificamente aos riscos para a saúde humana, o Instituto Nacional do Câncer (INCA), por exemplo, já alertou a sociedade brasileira para o fato de que, considerando o potencial cancerígeno (em longo prazo) e intoxicante (em curto prazo), a atitude mais adequada é não utilizar agrotóxicos. Destacou ainda que proteções individuais ou barreiras locais não impedem que a substância atinja lençóis freáticos e atue em áreas muito distantes da original. Segundo o INCA, as medidas de controle são "paliativos que devem ser adotados em um período determinado, tendo em conta que uma política maior de proibição do uso e [de] estímulo a culturas livres de agrotóxico precisa ser implantada nas regiões" 27 .

Esse alerta do INCA reveste-se ainda de mais importância na medida em que, nos últimos anos, a emergência de um novo tipo de risco decorrente dos agrotóxicos - a desregulação endócrina - fez intensificar o debate sobre a necessidade de proteger a saúde e o meio ambiente. Os desreguladores endócrinos são:

(...) substâncias (incluindo vários pesticidas) suspeitas de interferirem com os sistemas endócrinos dos seres humanos e dos animais selvagens e que podem causar efeitos nocivos para a saúde tais como cancro, alterações comportamentais e anomalias reprodutivas, mesmo que a exposição não exceda doses extremamente baixas ${ }^{28}$.

Assim, além do já conhecido risco de intoxicação, há também outros efeitos adversos decorrentes dos agrotóxicos, os quais antes não eram sequer imaginados.

Segundo a Organização Internacional do Trabalho (OIT), estima-se que os agrotóxicos causem anualmente 70 mil intoxicações agudas e crônicas que evoluem para óbito e um número muito maior de doenças agudas e crônicas não fatais ${ }^{29}$.

Com relação à intoxicação, esta pode se dar por exposição direta ou indireta. A direta é aquela que incide sobre os operários da indústria de agrotóxicos e os operadores que os utilizam; a indireta é aquela que, por sua vez, atinge os consumidores e as pessoas que se encontram nas proximidades de onde o pesticida é aplicado ${ }^{30}$.

\footnotetext{
${ }^{26}$ NODARI, Rubens Onofre. op. cit., p. 116.

${ }^{27}$ INSTITUTO NACIONAL DO CÂNCER (BRASIL). Coordenação de Prevenção e Vigilância. Vigilância do câncer relacionado ao trabalho e ao ambiente. 2. ed. rev. atual. Rio de Janeiro: INCA, 2010. p. 14.

${ }^{28}$ COMISSÃO DAS COMUNIDADES EUROPEIAS. Comunicação da Comissão ao Conselho, ao Parlamento Europeu e ao Comitê Econômico e Social. Para uma estratégia temática da utilização sustentável dos Pesticidas, cit., p. 14.

${ }^{29}$ INTERNATIONAL LABOR ORGANIZATION (ILO). World day for safety and health at work: a background paper. Geneva: International Labour Office, 2005. p. 7.

${ }^{30}$ COMISSÃO DAS COMUNIDADES EUROPEIAS. Comunicação da Comissão ao Conselho, ao Parlamento Europeu e ao Comitê Econômico e Social. Para uma estratégia temática da utilização sustentável dos Pesticidas, cit., p. 13.
} 
No que se refere à exposição direta, os efeitos adversos mais comumente observados nos trabalhadares e operadores incluem: dores de cabeça, vômitos, dores de estômago e diarreia, provocados pela exposição no decurso da aplicação, da preparação ou mistura e da manipulação dos recipientes ${ }^{31}$. Ainda quanto aos riscos oriundos da exposição direta, deve-se destacar que estudos científicos já comprovaram haver relação entre a utilização de agrotóxicos e a tentativa de suicídio. Estimativas recentes mostram que ocorrem entre 234 mil e 326 mil suicídios relacionados aos agrotóxicos por ano no mundo, contribuindo com aproximadamente um terço de todos os suicídios globalmente ${ }^{32}$.

No contexto brasileiro, conforme mencionam Pires, Caldas e Recena, as tentativas de suicídio relacionadas à exposição frequente de seres humanos aos agrotóxicos ocorridas entre janeiro 1992 e dezembro 2002, no Mato Grosso do Sul, foram avaliadas com base nos registros das notificações de intoxicação fornecidas pelo Centro Integrado de Vigilância Toxicológica da Secretaria de Saúde do Estado $^{33}$. De acordo com esses dados, verificou-se a existência de 1.355 notificações de intoxicação, das quais 506 resultaram em tentativas de suicídio com 139 óbitos. Nesse mesmo sentido, Almeida afirma que "inúmeros têm sido os casos de tentativa de suicídio com agrotóxicos", havendo casos de "envenenamentos intencionais registrados com praticamente todos os tipos de agrotóxicos (inseticidas, herbicidas, fungicidas, rodenticidas etc.)"34.

No que se refere à exposição indireta, convém destacar que a contaminação dos alimentos ainda é um problema em diversos países. Na União Europeia, o fungicida procimidone, que não é mais utilizado nessa zona econômica, foi relatado diversas vezes em produtos provenientes da Turquia e da Jordânia, conforme relatório produzido em 2011 pela Comissão Europeia ${ }^{35}$. Em 2009, por sua vez, foi constatado que substâncias proibidas na União Europeia estavam presentes nas maçãs oriundas do Brasil ${ }^{36}$.

${ }^{31}$ COMISSÃO DAS COMUNIDADES EUROPEIAS. Comunicação da Comissão ao Conselho, ao Parlamento Europeu e ao Comitê Econômico e Social. Para uma estratégia temática da utilização sustentável dos Pesticidas, cit., p. 12.

${ }^{32}$ GUNNEL, David; EDDLESTON, Michael, PHILLIPS, Michael R; KONRADSEN, Flemming. The global distribution of fatal pesticide self-poisoning: systematic review. BMC Public Health, p. 1, 2007. Disponível em: <http://www.biomedcentral.com/1471-2458/7/357>. Acesso em: 24 nov. 2011.

${ }^{33}$ PIRES, Dario Xavier Pires; CALDAS, Eloísa Dutra Caldas; RECENA, Maria Celina Piazza. Uso de agrotóxicos e suicídios no Estado do Mato Grosso do Sul, Brasil. Disponível em: <http://www.scielosp.org/scielo. php?pid=S0102-311X2005000200027\&script=sci_arttext>. Acesso em: 09 jun. 2012.

${ }^{34}$ ALMEIDA, Pedro José de. op. cit., p. 42.

${ }^{35}$ EUROPEAN COMISSION. The Rapid Alert System for Food and Feed (RASFF). Luxembourg: Office for Official Publications of the European Communities, 2011. p. 13.

${ }^{36}$ AGÊNCIA NACIONAL DE VIGILÂNCIA SANITÁRIA. Programa de Análise de Resíduos de Agrotóxicos em Alimentos (PARA). Relatório de Atividades de 2010. p. 13. Disponível em: <http://portal.anvisa.gov.br/ wps/wcm/connect/b380fe004965d38ab6abf74ed75891ae/Relatório+PARA+2010+-+Versão+Final. pdf?MOD=AJPERES>. Acesso em: $16 \mathrm{dez} .2011$. 
No Brasil, a situação não é diferente, uma vez que pesticidas ainda são encontrados em quantidades consideradas inadequadas em muitos dos alimentos analisados pela Agência Nacional de Vigilância Sanitária (Anvisa) anualmente ${ }^{37}$.

Em virtude da periculosidade desses compostos químicos, o objetivo de muitos estudos recentes tem sido expandido para não apenas caracterizar os riscos à saúde dos aplicadores autorizados, mas também de seus cônjuges e de outros membros da família. Os tipos de efeitos para a saúde avaliados para aqueles expostos aos pesticidas também têm sido ampliados. Enquanto os estudos anteriores focavam em identificar efeitos agudos na saúde - incluindo dor de cabeça, suores, tremores, vômitos, rachaduras e outros sintomas em grande parte associados a sintomas neurológicos agudos ou reações dermatológicas, respectivamente --, um maior conjunto de possibilidades e de efeitos na saúde em longo prazo tem sido avaliado. Entre eles, encontram-se: doença respiratória, a exemplo da asma; perda de visão, decorrente de degeneração da retina; doença de Parkinson, doença degenerativa neurológica; artrite reumatoide e outras doenças autoimunes; problemas para a reprodução, incluindo efeitos na fertilidade e nos ciclos de reprodução; e câncer (mais de 20 tipos estão sendo estudados) ${ }^{38}$.

Em 2004, uma equipe médica do Canadá publicou um trabalho científico intitulado Revisão da literatura sobre pesticidas: Uma revisão sistemática dos efeitos dos pesticidas na saúde humana, com as seguintes conclusões, retiradas de trabalhos científicos publicados entre 1993 e 2004: a saúde das crianças é particularmente afetada pela exposição a agrotóxicos e também indiretamente, a partir da exposição de seus pais (a exposição dos pais a pesticidas está relacionada a defeitos congênitos, natimortos e desenvolvimento anormal do feto). Além desses resultados, verificou-se uma associação entre determinados tipos de pesticidas e doenças do sistema nervoso ou transtornos mentais, bem como uma associação significativa entre a exposição a pesticidas e o desenvolvimento de câncer de cérebro, próstata, rins e pâncreas. Finalmente, observou-se ainda que o herbicida 2,4-D e/ou clorofenóis levaram a um aumento na incidência de linfoma não Hodgkin e que a exposição a pesticidas e a leucemia foram significativamente associadas ${ }^{39}$.

A Organização Mundial da Saúde (OMS), por sua vez, já alertou para o fato de que os fetos, bebês e crianças são mais suscetíveis aos pesticidas do que os adultos porque seus corpos ainda estão em desenvolvimento e porque sua dieta e

\footnotetext{
${ }^{37}$ AGÊNCIA NACIONAL DE VIGILÂNCIA SANITÁRIA. Programa de Análise de Resíduos de Agrotóxicos em Alimentos (PARA). Relatório de Atividades de 2010, cit., p. 13.

${ }^{38}$ SNEDEKER, Suzanne M. Precautionary Pesticide Selection. American Nurseryman, v. 203, n. 3, 2006. p. 26.

${ }^{39}$ SANBORN, M; COLE, D; KERR, K; VAKIL, C; SANIN; LH; BASSIL, K. Pesticides literature review: Systematic review of pesticide human health effects. Toronto: The Ontario College of Family Physicians, 2004. p. 1-186. Disponivel em: <http://www.ocfp.on.ca/docs/public-policy-documents/pesticides-literature-review.pdf?Status=Master>. Acesso em: 20 jan. 2012.
} 
seus padrões de comportamento especiais muitas vezes resultam em uma maior exposição a esses produtos ${ }^{40}$.

A respeito do tema, convém mencionar que no Brasil há registro de contaminação de leite materno por agrotóxicos. Nesse sentido, foi realizada uma pesquisa com 62 nutrizes da cidade de Lucas do Rio Verde, em Mato Grosso, e se verificou que em todas as amostras existia pelo menos um tipo de agrotóxico analisado ${ }^{41}$. Confirma-se, portanto, que os riscos decorrentes dos agrotóxicos estão, inclusive, ameaçando a vida daqueles que acabaram de nascer e que são mais vulneráveis.

Além disso, há diversos outros estudos científicos que apontam para a gravidade dos riscos dessas substâncias. Recentemente, um estudo realizado na Califórnia apresentou evidências de uma associação entre o câncer de próstata e a exposição a pesticidas em ambientes com essas substâncias e em casas ao redor de áreas intensivamente agrícolas. A associação aparece espeficamente para compostos com um papel biológico plausível na carcinogênese da próstata ${ }^{42}$.

Outro estudo, também recente, confirma a associação entre o diabetes tipo 2 e a exposição de adultos a pesticidas organoclorados em uma população urbana geral ${ }^{43}$.

Realizadas essas considerações acerca dos riscos decorrentes dos agrotóxicos, serão estudadas no próximo item as contribuições desses químicos para a configuração de uma sociedade de risco.

\section{Contribuições dos agrotóxicos para a configuração de uma sociedade de risco}

Deve-se destacar que as características dos efeitos adversos dos agrotóxicos se encaixam perfeitamente no tipo de risco aos quais as sociedades modernas estão expostas. Segundo Beck, nessa sociedade houve uma explosão de riscos, cujos efeitos tendem cada vez mais a se evadir das instituições de controle e proteção

\footnotetext{
${ }^{40}$ WORLD HEALTH ORGANIZATION REGIONAL OFFICE FOR EUROPE AND EUROPEAN ENVIRONMENT AGENCY. Children's health and environment: a review of evidence. Luxembourg: European Environment Agency Series, 2002. p. 63.

${ }^{41}$ PALMA, DCA. Agrotóxicos em leite humano de mães residentes em Lucas do Rio Verde - MT. Dissertação (Mestrado) - UFMT/ISC, Cuiabá, 2011.

${ }^{42}$ COCKBURN, Myles; MILLS, Paul; ZHANG, Xinbo; ZADNICK, John; GOLDBERG, Dan and RITZ, Beate. Prostate cancer and ambient pesticide exposure in agriculturally intensive areas in California. Am. J. Epidemiol, v. 173, n. 11, 1280, 2011. Disponível em: <http://aje.oxfordjournals.org/content/173/11/1280>. Acesso em: 23 nov. 2011.

${ }^{43}$ AIRAKSINEN, Riikka; RANTAKOKKO, Panu; ERIKSSON, Johan G. ; BLOMSTEDT, Paul; KAJANTIE, Eero and KIVIRANTA, Hannu. Association Between Type 2 Diabetes and Exposure to Persistent Organic Pollutants. Diabetes Care, n. 34, Sept. 2011. Disponível em: <http://care.diabetesjournals.org/content/34/9/1972. abstract?sid=ef092fe7-b7d9-431c-afc13c0f806e1fce>. Acesso em: 24 nov. 2011.
} 
da sociedade industrial ${ }^{44}$. Em adição aos riscos típicos da sociedade industrial, os riscos ambientais oriundos das engenharias nuclear, química, ambiental e genética, característicos de uma sociedade pós-industrial, assumem características distintas, a saber: são ilimitados em função do tempo, globais no âmbito de seu alcance e potencialmente catastróficos ${ }^{45}$. Nesse sentido, examina-se o caso dos agrotóxicos: a introdução deliberada desses produtos no meio ambiente tem levado à presença de alguns compostos, embora em concentrações muito baixas, em quase todas as áreas do globo, tais como as regiões polares, que se localizam longe dos locais de aplicação $0^{46}$.

Convém registrar que, no caso especificamente desses produtos químicos, também típicos de uma sociedade pós-industrial, foi com a publicação do livro Primavera Silenciosa ${ }^{47}$, em 1962 pela bióloga norte-americana Rachel Carson, que surgiu uma preocupação mais generalizada com o potencial lesivo dessas substâncias, principalmente acerca da persistência desses produtos no ambiente ${ }^{48} \mathrm{e}$ dos danos causados pelo inseticida Dicloro-Difenil-Tricloroetano, conhecido por DDT, contribuindo para que este fosse banido dos Estados Unidos já no ano de $1962^{49}$.

Em sua obra, Carson afirma que as "armas" utilizadas para destruir os insetos estavam também afetando o planeta Terra como um todo ${ }^{50}$. Passadas algumas décadas e apesar de muitas descobertas sobre seus efeitos adversos, a falta de conhecimento científico sobre o impacto de muitas substâncias químicas na saúde humana e no meio ambiente continua sendo motivo de preocupação ${ }^{51}$.

Casos como o do amianto, do benzeno e do DDT demonstram que nem sempre, no momento da inovação, é possível se apurarem todos os efeitos prejudiciais na saúde humana e no meio ambiente. Segundo o INCA, amianto (latim) ou asbesto (grego) são nomes genéricos de uma família de minérios encontrados profusamente na natureza e muito utilizados pelo setor industrial no último século ${ }^{52}$. De acordo

${ }^{44}$ BECK, Ulrich. A reinvenção da política: Rumo a uma teoria da modernização reflexiva. In: BECK, Ulrich; GIDDENS, Anthony; LASH, Scott (Orgs.). Modernização reflexiva: política, tradição e estética na ordem social moderna. São Paulo: Ed. da Universidade Estadual Paulista, 1997. p. 15.

${ }^{45}$ BECK, Ulrich. Risk Society and the Provident State. In: LASH, Scott; SZERSZYNSKI, Bronislaw; WYNNE, Brian (Eds.). Risk, environment and modernity: towards a new ecology. London: Sage Publications, 1998. p. 31.

${ }^{46}$ GREGOR, G. M. Deposition and accumation of selected agricultural pesticides in Canadian arctic snow. In: KURTZ, D.A. Long range transport of pesticides. Boca Raton, FL: Lewis Publishers, 1990. p. 386.

${ }^{47}$ CARSON, Rachel. Primavera silenciosa. São Paulo: Melhoramentos, 1964. p. 262.

${ }^{48}$ EUROPEAN ENVIRONMENT AGENCY. The precautionary principle in the 20th Century. Late lessons from Early Warnings. Edited by Poul Harremoës, David Gee, Malcolm MacGarvin, Andy Stirling, Jane Keys, Brian Wynne, Sofia Guedes Vaz. UK: Earthscan Publications, 2002. p. 116.

${ }^{49}$ SUNSTEIN, Cass R. Risk and reason. Safety, Law and the Environment. Cambridge, Mass.: Cambridge University Press 2002. p. 15.

${ }^{50}$ CARSON, Rachel. op. cit., p. 262.

${ }^{51}$ COMISSÃO DAS COMUNIDADES EUROPEIAS. Livro branco - Estratégia para a futura política em matéria de substâncias químicas. Bruxelas, 27.2.2001. COM (2001) 88 final. p. 5. Disponível em: <http://eur-lex. europa.eu/LexUriServ/site/pt/com/2001/com2001_0088pt01.pdf>. Acesso em: 09 maio 2011.

${ }_{5}^{5}$ INSTITUTO NACIONAL DO CÂNCER. Prevenção e detecção. Disponível em: <http://www1.inca.gov.br/conteudo_view.asp?ID=15>. Acesso em: 28 nov. 2011. 
com o Ministério da Saúde, benzeno é um hidrocarboneto aromático encontrado no estado líquido incolor, lipossolúvel, volátil, inflamável, de odor característico perceptível a concentrações de 12 ppm (parte por milhão), cuja fórmula molecular é C6H6, CAS 71-43-2, ONU n. 111453. O DDT, por sua vez, é um inseticida cujos efeitos foram inicialmente tornados públicos pela obra Primavera Silencios $a^{54}$.

A respeito dos efeitos adversos desses produtos, a Comissão das Comunidades Europeias já registrou:

\begin{abstract}
Algumas substâncias químicas têm causado danos graves na saúde humana, provocando sofrimento e morte prematura, bem como no ambiente. Exemplos bem conhecidos são o amianto, que se sabe ser causa de cancro do pulmão e de mesoteliomas, ou o benzeno, que provoca leucemia. Um uso abundante do DDT teve como resultado perturbações na reprodução das aves. Embora estas substâncias tenham sido totalmente proibidas ou sujeitas a outros controlos, as medidas só foram tomadas depois da ocorrência dos danos, dado não se dispor de conhecimentos sobre os impactos adversos dessas substâncias químicas antes de estas serem utilizadas em grandes quantidades ${ }^{55}$.
\end{abstract}

No caso dos agrotóxicos, a exemplo do ocorreu com o inseticida DDT, é comum uma substância ser amplamente utilizada para, somente após um longo período de tempo, ser banida, em virtude da posterior descoberta de seus riscos para a saúde e/ou o meio ambiente.

Convém lembrar que, passadas mais de quatro décadas do alerta de Carson, o Programa das Nações Unidas para o Meio Ambiente publicou recentemente (no ano de 2012) relatório intitulado Ação urgente necessária para reduzir crescentes riscos para a saúde e o meio ambiente decorrentes dos químicos, no qual destacou que as principais preocupações ambientais incluem a contaminação dos rios e lagos por agrotóxicos e fertilizantes e a poluição por metais pesados associados ao cimento e à produção têxtil, bem como a contaminação por dioxina decorrente da mineração ${ }^{56}$.

Apesar dos vários estudos científicos relacionados aos efeitos adversos à saúde humana, as empresas produtoras de agroquímicos tendem a rebater as críticas aos efeitos danosos de seus insumos, procurando mostrar que os problemas ambientais e de contaminação humana são “decorrentes do uso inadequado ou da não observância

\footnotetext{
${ }^{53}$ BRASIL. MINISTÉRIO DA SAÚDE. Câncer relacionado ao trabalho: leucemia mielóide aguda - síndrome mielodisplásica decorrente da exposição do benzeno. Brasília: Ed. do Ministério da Saúde, 2006. p. 10.

${ }^{54}$ CARSON, Rachel. op. cit.

${ }^{55}$ COMISSÃO DAS COMUNIDADES EUROPEIAS. Livro branco - Estratégia para a futura política em matéria de substâncias químicas, cit., p. 4.

${ }^{56}$ UNITED NATIONS ENVIRONMENT PROGRAMME (UNEP). Urgent Action Needed to Reduce Growing Health and Environmental Hazards from Chemicals: UN Report. 5 Set. 2012. Disponível em: <http://www.unep. org/newscentre/Default.aspx?DocumentID=2694\&ArticlelD=9266\&l=en>. Acesso em: 10 out. 2012.
} 
das normas técnicas de aplicação dos agrotóxicos", e não decorrentes da composição química dos produtos ${ }^{57}$. No entendimento de Garcia, trata-se de um enfoque simplista e maniqueísta que transfere ao usuário praticamente toda a responsabilidade pela contaminação ambiental e dos alimentos e por sua própria intoxicação ${ }^{58}$.

A mídia, da mesma forma, nem sempre reflete o interesse público quando trata do tema. É o que se infere da reportagem publicada em 2012 pela revista Veja, cujo trecho abaixo se extrai:

A palavra "Agrotóxico" é imprecisa e algo carregado ao julgamento de um valor - resquício do tempo, há muito tempo deixado para trás, em que estas substâncias eram colocadas no mercado sem pesquisa suficiente sobre suas propriedades e seus efeitos, e usadas de forma indiscriminada. O nome certo é "defensivo agrícola", uma vez que esses produtos servem não para intoxicar a lavoura ou o produtor, mas sim para defender a plantação de pragas, insetos e parasitas e evitar que ela se perca ${ }^{59}$.

Trata-se de mais um exemplo do fenômeno da irresponsabilidade organizada, citado anteriormente. Diante dos riscos de tais produtos, a nomenclatura "defensivos agrícolas" tornou-se obsoleta, contrariamente ao que a revista Veja deixou estampado em sua reportagem.

Os estudos científicos mais recentes têm demonstrado que os danos e riscos ocasionados para a saúde e o meio ambiente não são poucos. Trata-se de externalidades ${ }^{60}$ negativas geradas pela utilização dos agrotóxicos e cujos custos de reparação acabam sendo socializados pelo Estado ${ }^{61}$. Isso porque os principais beneficiários da utilização desses produtos não são necessariamente aqueles que suportam os custos externos ligados aos efeitos adversos (nomeadamente os efeitos ambientais) dessa utilização ${ }^{62}$.

\footnotetext{
${ }^{57}$ EHLERS, Eduardo. O que é agricultura sustentável? São Paulo: Brasiliense, 2008. p. 31.

${ }^{58}$ GARCIA, Eduardo Garcia. Todo cuidado é pouco. Le monde Diplomatique, Instituto Pólis, São Paulo, abr. 2010. p. 7.

${ }^{59}$ GUIA VEJA. A verdade sobre os agrotóxicos. Veja, São Paulo, 4 jan. 2012. p. 84.

${ }^{60}$ Deve-se lembrar de que o uso dos bens ambientais dá origem ao que os economistas chamam de externalidades, sejam elas positivas, sejam negativas. Nesse sentido, Sadeleer traz alguns exemplos. Segundo o autor, agricultores que vivem perto de uma floresta bem mantida se beneficiam da redução da erosão e de poços que não secam. Dessa maneira, os agricultores podem desfrutar de externalidades positivas. Por outro lado, as externalidades negativas surgem quando a produção ou o consumo de bens ou serviços causam danos aos bens ambientais sem que o dano seja refletido em seu preço. Por exemplo, quando ocorre o uso excessivo de fertilizantes e de pesticidas, uso este que causa a poluição dos recursos hídricos. SADELEER, Nicolas. Environmental principles. From political slogans to legal rules. Oxford; New York: Oxford University Press, 2008. p. 23.

${ }^{61}$ SOARES, Wagner Lopes; PORTO, Marcelo Firpo. Atividade agrícola e externalidade ambiental: uma análise a partir do uso de agrotóxico no cerrado brasileiro. Ciên. Saúde Coletiva, Rio de Janeiro, v. 12, n. 1, p. 1, jan./mar. 2007.

${ }^{62}$ COMISSÃO DAS COMUNIDADES EUROPEIAS. Comunicação da Comissão ao Conselho, ao Parlamento Europeu e ao Comitê Econômico e Social. Para uma estratégia temática da utilização sustentável dos Pesticidas, cit., p. 15.
} 
Verifica-se, nesse contexto, que há uma privatização dos lucros e uma socialização dos riscos, bastando para tanto registrar que quem arca com o tratamento das doenças ocasionadas pelos pesticidas é a própria sociedade. A esse respeito, Soares ensina que, apesar de não serem facilmente percebidos, os custos podem ser vislumbrados nas planilhas do Ministério da Saúde de repasse de verba para o atendimento médico-hospitalar no Sistema Único de Saúde (SUS) e nas despesas do Ministério da Previdência Social para concessão dos benefícios, entre outros gastos ${ }^{63}$. Recentemente, um estudo compilou informações e examinou os custos das externalidades resultantes do uso de pesticidas em quatro países - Alemanha, Estados Unidos, China e Reino Unido. No Reino Unido, por exemplo, verificou-se que o total gasto com os custos externos oriundos desses produtos é estimado em 257 milhões de dólares; na Alemanha, o valor foi estimado em 166 milhões de dólares; nos Estados Unidos, em um bilhão e 492 milhões de dólares; e, na China, somente para o arroz, um bilhão e 398 milhões de dólares. Nestes dois últimos países, os resultados foram baseados em suposições conservadoras, especialmente porque não havia informação acerca das exposições crônicas das pessoas aos pesticidas ${ }^{64}$.

De acordo com o relatório Ação Urgente necessária para reduzir crescentes riscos para a saúde e o meio ambiente decorrentes dos químicos, entre 2005 e 2020, o custo acumulado de doenças e lesões ligadas aos pesticidas na agricultura de pequena escala na África Subsaariana poderia chegar a 90 bilhões de dólares ${ }^{65}$.

No Brasil, da mesma forma, um estudo realizado no Paraná estimou que, para cada dólar gasto com a compra de agrotóxicos no estado, cerca de um dólar e 28 centavos poderiam ser gerados em custos externos por intoxicação ${ }^{66}$.

Nesse cenário, os agrotóxicos contribuem para a configuração de uma sociedade de risco. Segundo Beck, essa sociedade pode ser definida como uma fase do desenvolvimento da sociedade moderna, em que os riscos sociais, políticos, econômicos e individuais tendem cada vez mais a escapar das instituições de controle e proteção da sociedade industrial ${ }^{67}$. De acordo com Goldblatt ${ }^{68}$, o termo irresponsabilidade organizada é utilizado por Beck para descrever os meios pelos quais os sistemas político e judicial das sociedades de risco, intencional ou involuntariamente,

\footnotetext{
${ }^{63}$ SOARES, Wagner Lopes. Uso dos agrotóxicos e seus impactos à saúde e ao ambiente: uma avaliação integrada entre a economia, a saúde pública, a ecologia e a agricultura. Tese (Doutorado) - Programa de Pós-Graduação da Escola Nacional de Saúde Pública Sergio Arouca. Rio de Janeiro, 2010. p. 9.

${ }^{64}$ PRETTY, Jules; WAIBEL, Herrmann. Paying the price: the full cost of pesticides. In: PRETTY, J. (Ed.). The pesticide detox. London: Earthscan, 2005. p. 54.

${ }^{65}$ UNITED NATIONS ENVIRONMENT PROGRAMME (UNEP). Urgent Action Needed to Reduce Growing Health and Environmental Hazards from Chemicals: UN Report. 5 Set. 2012, cit.

${ }^{66}$ SOARES, Wagner Lopes. op. cit., p. 51.

${ }^{67} \mathrm{BECK}$, Ulrich. A reinvenção da política: Rumo a uma teoria da modernização reflexiva, cit., p. 15.

${ }^{68}$ GOLDBLATT, David. op. cit., p. 240.
} 
tornam invisíveis as origens e consequências sociais dos perigos ecológicos em grande escala. Agindo dessa forma, as instituições típicas da sociedade industrial buscam alcançar dois objetivos principais: (a) eximir-se da culpa e da responsabilidade diante da produção de riscos e de seus possíveis efeitos secundários; e (b) desviar e controlar os protestos que poderiam advir do conhecimento da realidade da catástrofe ${ }^{69}$.

Nessa sociedade, os riscos são, em muitos casos, subtraídos à percepção humana e residem na esfera das fórmulas físico-químicas, como, por exemplo, a ameaça nuclear e os elementos tóxicos dos alimentos ${ }^{70}$. A respeito do tema, convém lembrar o que Wargo afirma ao se referir sobre a invisibilidade dos riscos dos agrotóxicos. Segundo o autor, para os agricultores a decisão de utilizar os pesticidas pode parecer perfeitamente racional, porém essa escolha contém riscos não percebidos pelos sentidos humanos ${ }^{71}$.

Ao examinar a questão, Beck alerta para o fato de que se faz necessário levar em consideração que substâncias nocivas idênticas ou semelhantes podem ter um impacto completamente distinto em pessoas diferentes, de acordo com a idade, o sexo, os hábitos alimentares, o tipo de trabalho, a informação, o nível de educação etc. Sobre esse aspecto, o autor afirma que a miséria e a cegueira frente ao risco coincidem. Para exemplificar tal afirmação, traz o depoimento de um agricultor da Ilha de Trindade que utilizava o inseticida DDT com as mãos: "Se não te sentes mal depois de ter apertado o spray, é que não apertastes o suficiente" "72.

Realizadas essas considerações acerca da contribuição dessas substâncias para a construção de uma sociedade de risco, passa-se, a seguir, ao estudo de regulação da pulverização aérea no Brasil.

\section{A pulverização aérea de agrotóxicos: uma análise da regulação pertinente}

No dia 3 de maio de 2013, teve-se notícia de que, em decorrência de erro de uma aeronave de pulverização agrícola da empresa Aerotex, liberaram-se agrotóxicos sobre a Escola Municipal Rural de Ensino Fundamental São José do Pontal, localizada no Assentamento Pontal dos Buritis, a 106 quilômetros de Rio Verde, em Goiás. Trinta e cinco estudantes e dois professores tiveram de ser levados ao hospital, em virtude de sintomas como dores de cabeça, formigamento nos braços e falta de $\mathrm{ar}^{73}$.

\footnotetext{
${ }^{69}$ LEITE, José Rubens Morato; AYALA, Patryck. Direito ambiental na sociedade de risco. Rio de Janeiro: Forense Universitária: 2004. p. 12.

${ }^{70}$ BECK, Ulrich. La sociedad de riesgo: hacia uma nueva modernidad. Buenos Aires: Paidós, 1998. p. 28.

${ }^{71}$ WARGO, John. Our children's toxic legacy. How science and law fail to protect us from pesticides? 2. ed. New Haven: Yale University Press, 1998. p. xi.

${ }^{72}$ BECK, Ulrich. La sociedad de riesgo: hacia uma nueva modernidade, cit., p. 48.

${ }^{73}$ RIO VERDE AGORA. Alunos de escola atingida por agrotóxicos passam bem. 3 maio 2013. Disponível em: <http://www.rioverdeagora.com.br/noticias/cidade/alunos-de-escola-rural-atingida-por-agrotoxico-passam-bem>. Acesso em: 08 maio 2013.
} 
Na reportagem veiculada na internet, consta que “(...) alunos e servidores passam bem e, segundo informações iniciais, não será necessária a transferência deles para hospitais de Rio Verde e região". Entretanto, a questão não pode ser colocada de uma maneira tão simples assim, pois já foi demonstrado que existe uma série de riscos oriundos dessas substâncias, sendo que muitos dos efeitos adversos se manifestam somente muito tempo depois.

Esse fato ocorrido recentemente no Brasil só vem reforçar a importância da proibição da pulverização aérea no Brasil. Nesse sentido, deve-se lembrar de que a Lei n. 7.802/1989 nada regulou acerca do tema. Entretanto, diante dos consideráveis danos ao meio ambiente decorrentes da pulverização aérea desses produtos, a aplicação dos princípios da prevenção e da precaução impõe a proibição de tal atividade, principalmente porque existem outras alternativas - como a aplicação terrestre de tais produtos ou a utilização de outras técnicas de cultivo que não envolvam a utilização de agrotóxicos.

Nesse sentido, convém lembrar, conforme já analisado no primeiro capítulo, que a Embrapa apresentou estudos que comprovam a alta periculosidade da pulverização aérea. Segundo a empresa, normalmente ocorre uma "deriva técnica", de maneira que os atuais equipamentos de pulverização - mesmo com calibração, temperatura e ventos ideais - deixam uma percentagem considerável dos agrotóxicos pulverizados retidos nas plantas e no solo, além da percentagem que, através do ar, atinge áreas circunvizinhas da aplicação ${ }^{74}$.

Além desse estudo, também já foi constatado, através de pesquisa científica publicada na década de 1990, que a deriva decorrente da aplicação aérea de agrotóxicos já atingiu uma distância de 32 quilômetros da área-alvo, o que também reforça o dever estatal de proibir essa atividade ${ }^{75}$.

A Associação Brasileira de Saúde Coletiva (Abrasco), por sua vez, ao tratar do tema, assinalou que é imperativo que o poder público proíba tal atividade, diante das doses cada vez maiores de contaminantes nos produtos tóxicos que têm sido aplicados principalmente em áreas de monocultura, gerando agravos à saúde humana e à dos ecossistemas ${ }^{76}$.

A legislação federal que regula os agrotóxicos não proíbe tal atividade. Diferentemente, em muitos países a proibição da pulverização aérea já é uma realidade, a exemplo da Eslovênia ${ }^{77}$.

\footnotetext{
${ }^{74}$ CHAIM, Aldemir. op. cit., p. 317.

${ }^{75}$ PIMENTEL, David. op. cit., p. 25.

${ }^{76}$ ASSOCIAÇÃO BRASILEIRA DE SAÚDE COLETIVA. Dossiê ABRASCO. Um alerta sobre os impactos dos agrotóxicos na saúde. Parte 1 - Agrotóxicos, segurança alimentar e saúde. Rio de Janeiro: ABRASCO, 2012. p. 59.

${ }^{77}$ PESTICIDE ACTION NETWORK EUROPE. NAP BEST PRACTICE. Sustainable use of pesticides. Implementing a National Action Plan. p. 21. Disponível em: <http://www.pan-europe.info/Resources/Reports/NAP_ best_practice.pdf>. Acesso em: 21 fev. 2013.
} 
As leis estaduais também não proíbem a pulverização aérea, com exceção da Lei n. $414 / 1993^{78}$, do Distrito Federal, que determinava a proibição da aplicação aérea ou por pivô central de agrotóxicos, em seu artigo 13, nos seguintes termos: "Em face das peculiaridades do Distrito Federal e suas características de ocupação do solo, é vedada a aplicação de agrotóxicos, seus componentes e afins, por via aérea ou através de pivô central".

Diante dos danos decorrentes da aplicação aérea, a regra em comento ajusta-se aos princípios ambientais aptos a enfrentar os riscos oriundos dos agrotóxicos. Infelizmente, em 1998, verificou-se um retrocesso ambiental na lei do Distrito Federal, uma vez que a regra foi flexibilizada: a Lei n. 2.124/1998 determinou que o artigo 13 da Lei n. 414/1993 passasse a vigorar com a seguinte redação:

Art. 13. Fica vedada a aplicação de agrotóxicos, seus componentes e afins, por via aérea ou por meio de pivô central, em face das características de ocupação do solo e das peculiaridades do Distrito Federal, salvo em casos excepcionais, considerados a extensão da área e o tipo e a quantidade da praga, com utilização exclusiva de agrotóxicos das classes III e IV, devidamente justificada, acompanhada e fiscalizada nos termos do Decreto-Lei n. 917, de 7 de outubro de 1969, regulamentado pelo Decreto n. 86.765, de 22 de dezembro de 1981. (Destaque da autora).

Como se verifica, no Distrito Federal, a partir da nova regra instituída pela Lei n. 2.124/1998, permitiu-se, em determinadas circunstâncias, a aplicação aérea de agrotóxicos ou por meio de pivô central.

Interessa registrar que não há no corpo da lei uma justificativa sequer para essa alteração legislativa. Dessa forma, e considerando-se os danos decorrentes da atividade, verifica-se que a edição de uma norma como a ora referida não observa o princípio da proibição de retrocesso ambiental. De acordo com Sarlet e Fensterseifer, embora não exista referência expressa na Constituição Federal, o princípio em questão consiste em um princípio constitucional implícito, tendo como fundamento constitucional, entre outros, o princípio da dignidade humana ${ }^{79}$.

Examinando o tema, Benjamin esclarece que, embora o princípio da proibição de retrocesso ambiental não institua camisa de força ao legislador, impõe-lhe limites não discricionários a sua atuação ${ }^{80}$.

\footnotetext{
${ }^{78}$ DISTRITO FEDERAL. Lei n. 414, de 15 de janeiro de 1993. Dispõe sobre produção, armazenamento, comercialização, transporte, consumo, uso, controle, inspeção, fiscalização e destino final de agrotóxicos, seus componentes e afins no Distrito Federal e dá outras providências. Disponível em: < http://www.tc.df.gov. br/SINJ/Arquivo.ashx?id_norma_consolidado=48373>. Acesso em: 06 mar. 2015.

${ }^{79}$ SARLET, Ingo Wolfgang; FENSTERSEIFER, Tiago. Notas sobre a proibição de retrocesso em matéria (socio) ambiental. In: O PRINCÍPIO da proibição de retrocesso ambiental. Brasília: Senado Federal, 2011. p. 198.

${ }^{80}$ BENJAMIN, Antonio Herman Benjamin. Princípio da proibição de retrocesso ambiental. In: O PRINCÍPIO da proibição de retrocesso ambiental. Brasília: Senado Federal, 2011. p. 69.
} 
Interessa ainda notar que as demais normas estaduais nada dispõem sobre a aplicação aérea de agrotóxicos, com exceção da lei de Minas Gerais, que em seu artigo $9^{\circ}$ estabeleceu a obrigatoriedade de os órgãos competentes do sistema operacional da agricultura e de meio ambiente estabelecerem em regulamento normas técnicas para aplicação desses produtos, nas quais devem ser definidas, pelo menos: "I - distância mínima entre o local da aplicação e cidades, povoações, áreas rurais habitadas e moradias isoladas; II - distância mínima entre o local da aplicação e mananciais de abastecimento público, mananciais de água e agrupamentos de animais" ${ }^{31}$.

Finalmente, cumpre mencionar que, considerando-se o princípio da solidariedade que informa o federalismo legislativo brasileiro em matéria ambiental, dois municípios brasileiros editaram normas proibindo a pulverização aérea de agrotóxicos em seu território. Trata-se dos municípios de Nova Venécia e de Vila Valério, no Espírito Santo ${ }^{82}$. No município de Vila Valério, é a Lei n. 43/2011 que, em seu artigo $1^{\circ}$, estabeleceu a proibição ora mencionada, nos seguintes termos: "Ficam expressamente vedadas as pulverizações aéreas em regiões agrícolas de Vila Valério".

Além dessas disposições legais, já existe projeto de lei no mesmo sentido, elaborado pelo município de Pratânia, localizado no Estado de São Paulo ${ }^{83}$. A justicativa para o referido projeto traz os seguintes fundamentos: (a) estudos elaborados pela Embrapa, os quais comprovam que a pulverização aérea deixa cerca de $30 \%$ dos agrotóxicos retidos nas plantas e $49 \%$ no solo, enquanto $19 \%$ se expandem para áreas circunvizinhas à da aplicação; (b) precedente do Estado do Ceará, onde os ministérios públicos Federal, Estadual e do Trabalho ingressaram com ação civil pública na $15^{\mathrm{a}}$ Vara da Justiça Federal requerendo, em Limoeiro do Norte, a proibição da pulverização aérea na Chapada do Apodi; (c) precedentes de municípios do Espírito Santo, onde se verificou aplicação de agrotóxicos que atingiu pátios de escolas, praças e propriedades de agricultores familiares que não utilizam agrotóxicos na produção de alimentos para o estado; e (d) a agricultura do município de Pratânia é composta em grande parte por pequenas propriedades, algumas das quais produzem atualmente "café de alta qualidade, através do modo convencional, com ótimos resultados econômicos, menos nocivos à

\footnotetext{
${ }^{81}$ MINAS GERAIS. Lei n. 10.545, 13 de dezembro de 1991. Dispõe sobre a produção, a comercialização e o uso de agrotóxicos e afins e dá outras providências. Disponível em: <http://www.almg.gov. $\mathrm{br} /$ consulte/legislacao/completa/completa.html?tipo=LEI\&num=10545\&comp=\&ano=1991\&aba =js_textoAtualizado\#texto>. Acesso em: 27 fev. 2013.

${ }^{82}$ CAMPANHA PERMANENTE CONTRA OS AGROTÓXICOS E PELA VIDA. Aplicação aérea de agrotóxico passou a ser proibida também em Nova Venécia-ES. Disponível em: <http://contraagrotoxicosdf.wordpress. com/2011/10/09/aplicacao-aerea-de-agrotoxico-passou-a-ser-proibida-tambem-em-nova-venecia-es/>. Acesso em: 06 fev. 2013.

${ }^{83}$ MUNICÍPIO DE PRATÂNIA. Projeto de Lei n. 018/2012. Dispõe sobre a proibição do uso de aeronaves nas pulverizações aéreas de agrotóxicos nas lavouras do município de Pratânia/SP. Disponível em: <http:// www.camarapratania.com.br/proposituras/PROJETO-LEI-ORD-018-12.pdf>. Acesso em: 06 fev. 2013.
} 
saúde da população, em uma forma mais sustentável de se produzir, sem causar prejuízos ao meio ambiente" 84 .

Mencione-se ainda que no município de Limoeiro do Norte, localizado no Ceará, também foi editada lei municipal com o objetivo de proibir a pulverização aérea de agrotóxicos. Trata-se da Lei n. 1.478/2009, a qual, apesar da intensa organização popular, não foi mantida em vigor. Isso porque apenas três meses depois da aprovação da referida norma, o prefeito propôs à Câmara Municipal sua revogação ${ }^{85}$.

Observa-se, nesse caso, que a irresponsabilidade organizada pode ser verificada, uma vez que, apesar de a ciência demonstrar os graves danos ao meio ambiente e de existirem outras formas de se produzir (seja através da aplicação terrestre dos agrotóxicos seja por métodos não químicos de produção), uma medida preventiva não é imposta.

A jurisprudência brasileira, no caso envolvendo a colheita de cana-de-açúcar, já deixou consignada a necessidade de se privilegiarem formas de produção menos agressivas ao meio ambiente, conforme se infere do julgado abaixo:
AMBIENTAL - DIREITO FLORESTAL - AÇÃO CIVIL PÚBLICA - CANA-DE-AÇÚCAR - QUEIMADAS - ARTIGO 21, PARÁGRAFO ÚNICO, DA LEI N. 4771/65 (CÓDIGO FLO- RESTAL) E DECRETO FEDERAL N. 2.661/98 - DANO AO MEIO AMBIENTE - EXISTÊNCIA DE REGRA EXPRESSA PROIBITIVA DA QUEIMA DA PALHA DE CANA - EXCEÇÃO EXISTENTE SOMENTE PARA PRESERVAR PECULIARIDA- DES LOCAIS OU REGIONAIS RELACIONADAS À IDENTI- DADE CULTURAL - VIABILIDADE DE SUBSTITUIÇÃO DAS QUEIMADAS PELO USO DE TECNOLOGIAS MODER- NAS - PREVALÊNCIA DO INTERESSE ECONÔMICO NO PRESENTE CASO - IMPOSSIBILIDADE.

1. Os estudos acadêmicos ilustram que a queima da palha da cana-de-açúcar causa grandes danos ambientais e que, considerando o desenvolvimento sustentado, há instrumentos e tecnologias modernos que podem substituir tal prática sem inviabilizar a atividade econômica.

\footnotetext{
${ }^{84}$ MUNICÍPIO DE PRATÂNIA. Projeto de Lei n. 018/2012. Dispõe sobre a proibição do uso de aeronaves nas pulverizações aéreas de agrotóxicos nas lavouras do município de Pratânia/SP, cit.

${ }^{85}$ ASSOCIAÇÃO BRASILEIRA DE SAÚDE COLETIVA. Dossiê ABRASCO. Um alerta sobre os impactos dos agrotóxicos na saúde. Parte 2 - Agrotóxicos, saúde, ambiente e sustentabilidade. Rio de Janeiro, jun. 2012. p. 81. Disponível em: <http://www4.planalto.gov.br/consea/noticias/imagens-1/mesa-de-controversias-sobre-agrotoxicos/dossie-abrasco-parte-2/view>. Acesso em: 17 jan. 2013.
} 
2. A exceção do parágrafo único do artigo 27 da Lei n. 4.771/65 deve ser interpretada com base nos postulados jurídicos e nos modernos instrumentos de linguística, inclusive com observância - na valoração dos signos (semiótica) - da semântica, da sintaxe e da pragmática.

3. A exceção apresentada (peculiaridades locais ou regionais) tem como objetivo a compatibilização de dois valores protegidos na Constituição Federal/88: o meio ambiente e a cultura (modos de fazer). Assim, a sua interpretação não pode abranger atividades agroindustriais ou agrícolas organizadas, ante a impossibilidade de prevalência do interesse econômico sobre a proteção ambiental quando há formas menos lesivas de exploração.

Agravo regimental improvido ${ }^{86}$. (Destaques da autora).

Trata-se, portanto, de se aplicar a melhor tecnologia disponível, visando-se a menores danos para a saúde humana e o meio ambiente. Nesse caso, inclusive - além dos estudos da Embrapa demonstrando os danos oriundos da aplicação aérea de agrotóxicos -, a Abrasco já elencou como ponto prioritário para a gestão dos riscos dos agrotóxicos, em recente publicação sobre o tema, o fim da pulverização aérea ${ }^{87}$.

Nesse sentido, advoga-se pela nacionalização da regra que proíbe a pulverização de agrotóxicos, em virtude dos graves danos decorrentes dessa atividade, bem como da existência de outros métodos menos prejudiciais à saúde humana $\mathrm{e}$ ao meio ambiente, aplicando-se, portanto, a melhor tecnologia disponível. Segundo Aragão, sendo a tecnologia uma condição importante da proteção ambiental, o progresso tecnológico torna “imperativo, pela cláusula da Melhor Técnica Disponível (MTD), um acréscimo qualitativo da proteção ambiental sempre que o progresso tecnológico possibilite a proteção acrescida" 88 .

A esse respeito, cabe ressaltar que existem estudos demonstrando que a eficiência agronômica de uma agricultura mais sustentável já foi comprovada: foram examinadas, em 26 países, 62 iniciativas de proteção integrada das culturas, e os pesquisadores concluíram que há resultados promissores, indicando que

\footnotetext{
${ }^{86}$ BRASIL. SUPERIOR TRIBUNAL DE JUSTIÇA. AgRg nos EDcl no Recurso Especial no 1.094 .873 - SP. Filipe Salles Oliveira e outros versus Ministério Público do Estado de São Paulo. Rel. Min. Humberto Martins. Julgamento em: 04 de agosto de 2009. Disponível em: <http://www.stj.jus.br/SCON/jurisprudencia/ toc.jsp?tipo_visualizacao $=$ null\&livre $=$ cana-de-a $\% E 7 \% F A c a r+e+q u e i m a d a \& \& b=A C O R \& p=t r u e \& t=\& l=10$ $\& \mathrm{i}=10>$. Acesso em: 29 de jan. 2013.

${ }^{87}$ ASSOCIAÇÃO BRASILEIRA DE SAÚDE COLETIVA. Dossiê ABRASCO - um alerta sobre os impactos dos agrotóxicos na saúde, cit.

${ }^{88}$ ARAGÃO, Alexandra. Direito Constitucional do Ambiente da União Europeia. In: CANOTILHO, José Joaquim Gomes Canotilho; LEITE, José Rubens Morato (Orgs.). Direito constitucional ambiental brasileiro. 5. ed. São Paulo: Saraiva, 2012. p. 34.
} 
o uso de pesticidas pode ser reduzido sem perda nas colheitas ${ }^{89}$. Nesse sentido e considerando-se a existência inclusive de aplicação terrestre de pesticidas, tem-se que mister se faz proibir o uso de uma tecnologia tão agressiva para o homem e o meio ambiente como a pulverização aérea.

Essa restrição já foi imposta pela Eslovênia $e^{90}$ merece a consideração dos demais países.

\section{Considerações finais}

Passadas mais de cinco décadas da publicação Primavera Silenciosa, de Rachel Carson, verifica-se um cenário em que os desafios impostos à regulação do uso dos agrotóxicos ainda são consideráveis.

Com relação à atualidade do problema, deve-se lembrar de que, no dia 3 de maio de 2013 no Brasil, teve-se notícia de um acidente decorrente de pulverização aérea de agrotóxicos, conforme o portal de notícias Rio Verde Agora. Por conta desse acidente, 35 estudantes e dois professores que se encontravam em uma escola no Assentamento Pontal dos Buritis, em Goiás, tiveram de ser levados ao hospital, em virtude de sintomas como dores de cabeça, formigamento nos braços e falta de ar. A questão, portanto, requer uma maior atenção por parte dos operadores do direito, uma vez que está ameaçando a própria qualidade de vida da população brasileira.

Verificou-se que a aplicação aérea de agrotóxicos não se coaduna com os princípios de direito ambiental pertinentes, em especial o princípio da prevenção. Isso porque já há estudo publicado pela Embrapa, no ano de 2004, informando que, mesmo diante das melhores condições, a pulverização aérea de agrotóxicos ocasiona danos ao meio ambiente, em especial aos recursos hídricos, ao solo e à atmosfera. Ademais, também já foi publicado estudo científico na década de 1990 comprovando que a deriva decorrente da aplicação aérea de agrotóxicos já atingiu uma distância de 32 quilômetros da área-alvo, o que também reforça o dever estatal de proibir essa atividade.

Nesse sentido, considerando-se que existem outras formas de se produzir - seja com produtos químicos por pulverização terrestre, seja através de técnicas mais sustentáveis -, torna-se inadmissível - por força da operacionalização da melhor tecnologia disponível, decorrente da aplicação do princípio da prevenção - a permissão da pulverização aérea de agrotóxicos. Assim, recorde-se que dois municípios brasileiros, Vila Valério e Nova Venécia, no Espírito Santo, já editaram normas proibindo a pulverização aérea em seus territórios, devendo tal proibição ser estendida a todo território nacional.

\footnotetext{
${ }^{89}$ PRETTY, Jules; WAIBEL, Herrmann. op. cit., p. 54.

${ }^{90}$ PESTICIDE ACTION NETWORK EUROPE. NAP BEST PRACTICE. Sustainable use of pesticides. Implementing a National Action Plan, cit.
} 


\section{Referências}

AGÊNCIA NACIONAL DE VIGILÂNCIA SANITÁRIA. Programa de Análise de Resíduos de Agrotóxicos em Alimentos (PARA). Relatório de Atividades de 2010. Disponível em: <http://portal.anvisa.gov.br/wps/wcm/connect/b380fe004965d38ab6abf74ed75891ae/ Relatório+PARA+2010+-+Versão+Final.pdf?MOD=AJPERES>. Acesso em: 16 dez. 2011.

AIRAKSINEN, Riikka; RANTAKOKKO, Panu; ERIKSSON, Johan G. ; BLOMSTEDT, Paul; KAJANTIE, Eero and KIVIRANTA, Hannu. Association Between Type 2 Diabetes and Exposure to Persistent Organic Pollutants. Diabetes Care, n. 34, Sept. 2011. Disponível em: <http://care.diabetesjournals.org/content/34/9/1972.abstract?sid=ef092fe7-b7d9-431cafc13c0f806elfce $>$. Acesso em: 24 nov. 2011.

ALBERGONI, Leide; PELAEZ, Victor. Da Revolução Verde à agrobiotecnologia: ruptura ou continuidade de paradigmas? Revista de Economia, Curitiba, v. 33, n. 1, p. 31-53, jan./jun. 2007.

ALMEIDA, Pedro José de. Intoxicação por agrotóxicos. São Paulo: Organização Andrei Ed., 2002.

AMARO, Pedro. A política de redução dos riscos dos pesticidas em Portugal. Lisboa: ISA/PRESS, 2007.

ARAGÃO, Alexandra. Direito Constitucional do Ambiente da União Europeia. In: CANOTILHO, José Joaquim Gomes Canotilho; LEITE, José Rubens Morato (Orgs.). Direito constitucional ambiental brasileiro. 5. ed. São Paulo: Saraiva, 2012.

ASSOCIAÇÃO BRASILEIRA DE SAÚDE COLETIVA. Dossiê ABRASCO. Um alerta sobre os impactos dos agrotóxicos na saúde. Parte 1 - Agrotóxicos, segurança alimentar e saúde. Rio de Janeiro: ABRASCO, 2012.

Dossiê ABRASCO. Um alerta sobre os impactos dos agrotóxicos na saúde. Parte 2 - Agrotóxicos, segurança alimentar e saúde. Rio de Janeiro, jun. 2012. Disponível em: <http:// www4.planalto.gov.br/consea/noticias/imagens-1/mesa-de-controversias-sobre-agrotoxicos/ dossie-abrasco-parte-2/view>. Acesso em: 17 jan. 2013.

BECK, Ulrich. Ecological politics in an age of risk. Trad. Amos Weisz. Cambridge: Polity, 1995.

- A reinvenção da política: Rumo a uma teoria da modernização reflexiva. In: BECK, Ulrich; GIDDENS, Anthony; LASH, Scott (Orgs.). Modernização reflexiva: política, tradição e estética na ordem social moderna. São Paulo: Ed. da Universidade Estadual Paulista, 1997.

. Risk Society and the Provident State. In: LASH, Scott; SZERSZYNSKI, Bronislaw; WYNNE, Brian (Eds.). Risk, environment and modernity: towards a new ecology. London: Sage Publications, 1998.

La sociedad de riesgo: hacia uma nueva modernidad. Buenos Aires: Paidós, 1998.

BENJAMIN, Antonio Herman Benjamin. Princípio da proibição de retrocesso ambiental. In: O PRINCÍPIO da proibição de retrocesso ambiental. Brasília: Senado Federal, 2011. 
BRASIL. MINISTÉRIO DA SAÚDE. Câncer relacionado ao trabalho: leucemia mielóide aguda - síndrome mielodisplásica decorrente da exposição do benzeno. Brasília: Ed. do Ministério da Saúde, 2006.

CAMPANHA PERMANENTE CONTRA OS AGROTÓXICOS E PELA VIDA. Aplicação aérea de agrotóxico passou a ser proibida também em Nova Venécia-ES. Disponível em: <http:// contraagrotoxicosdf.wordpress.com/2011/10/09/aplicacao-aerea-de-agrotoxico-passou-a-serproibida-tambem-em-nova-venecia-es/>. Acesso em: 06 de fev. 2013.

CARSON, Rachel. Primavera silenciosa. São Paulo: Melhoramentos, 1964.

CHAIM, Aldemir. Tecnologia de aplicação de agrotóxicos: fatores que afetam a eficiência e o impacto ambiental. In: SILVA, Célia Maria Maganhotto de Souza; FAY, Elisabeth Francisconi (Orgs.). Agrotóxicos \& ambiente. Brasília: Embrapa; 2004.

COCKBURN, Myles; MILLS, Paul; ZHANG, Xinbo; ZADNICK, John; GOLDBERG, Dan and RITZ, Beate. Prostate cancer and ambient pesticide exposure in agriculturally intensive areas in California. Am. J. Epidemiol, v. 173, n. 11, 1280-1288, 2011. Disponível em: <http:// aje.oxfordjournals.org/content/173/11/1280>. Acesso em: 23 nov. 2011.

COMISSÃO DAS COMUNIDADES EUROPEIAS. Comunicação da Comissão ao Conselho, ao Parlamento Europeu e ao Comitê Econômico e Social. Para uma estratégia temática da utilização sustentável dos Pesticidas. Bruxelas, 1.7.2002. COM (2002) 349 final. Disponível em: <http://eurlex.europa.eu/LexUriServ/site/pt/com/2002/com2002_0349pt01.pdf>. Acesso em: 10 maio 2011.

Livro branco - Estratégia para a futura política em matéria de substâncias químicas. Bruxelas, 27.2.2001. COM (2001) 88 final. Disponível em: <http://eur-lex.europa.eu/ LexUriServ/site/pt/com/2001/com2001_0088pt01.pdf>. Acesso em: 09 maio 2011.

CORTE INTERNACIONAL DE JUSTIÇA. Letter from the ambassador of Ecuador (appointede) to the kingdom of the netherlands to the registrar of the International Court of Justice. The Hague, 31 Mar. 2008. Disponível em: <http://www.icj-cij.org/docket/files/138/14474.pdf\#view=FitH \&pagemode=none\&search=\%22herbicides\%22>. Acesso em: 29 nov. 2012.

DÉOUX, Suzanne e Pierre. Ecologia é a saúde. Lisboa: Instituto Piaget, [s.d.].

EHLERS, Eduardo. O que é agricultura sustentável? São Paulo: Brasiliense, 2008.

EUROPEAN COMISSION. The Rapid Alert System for Food and Feed (RASFF). Luxembourg: Office for Official Publications of the European Communities, 2011.

EUROPEAN ENVIRONMENT AGENCY. The precautionary principle in the 20th Century. Late lessons from Early Warnings. Edited by Poul Harremoës, David Gee, Malcolm MacGarvin, Andy Stirling, Jane Keys, Brian Wynne, Sofia Guedes Vaz. UK: Earthscan Publications, 2002.

GARCIA, Eduardo Garcia. Todo cuidado é pouco. Le monde Diplomatique, Instituto Pólis, São Paulo, abr. 2010. 
GODOY, R. C. B. de; OLIVEIRA, M. I. de. Agrotóxicos no Brasil: processo de registro, riscos à saúde e programas de monitoramento. Cruz das Almas: Embrapa Mandioca e Fruticultura Tropical, 2004. 30 p. (Embrapa e Mandioca e Fruticultura Tropical. Documentos, 134). Disponível em: <http://www.cnpmf. embrapa.br/publicacoes/folder/folder_nim_2006.pdf>. Acesso em: 02 out. 2011.

GOLDBLATT, David. Teoria social e ambiente. Lisboa: Instituto Piaget, 1996.

GREGOR, G. M. Deposition and accumation of selected agricultural pesticides in Canadian arctic snow. In: KURTZ, D.A. Long range transport of pesticides. Boca Raton, FL: Lewis Publishers, 1990.

GUIA VEJA. A verdade sobre os agrotóxicos. Veja, São Paulo, 4 jan. 2012.

GUNNEL, David; EDDLESTON, Michael, PHILLIPS, Michael R; KONRADSEN, Flemming. The global distribution of fatal pesticide self-poisoning: systematic review. BMC Public Health, 2007. Disponível em: <http://www.biomedcentral.com/1471-2458/7/357>. Acesso em: 24 nov. 2011.

INSTITUTO BRASILEIRO DE GEOGRAFIA E ESTATÍSTICA (IBGE). Indicadores de desenvolvimento Sustentável. Brasil 2010. Disponível em: <http://www.ibge.gov.br/home/ geociencias/recursosnaturais/ids/ids2010.pdf>. Acesso em: 06 set. 2010.

INSTITUTO NACIONAL DO CÂNCER. Coordenação de Prevenção e Vigilância. Vigilância do câncer relacionado ao trabalho e ao ambiente. 2. ed. rev. atual. Rio de Janeiro: INCA, 2010.

. Prevenção e detecção. Disponível em: <http://www1.inca.gov.br/conteudo_view. asp?ID=15>. Acesso em: 28 nov. 2011.

INTERNATIONAL LABOR ORGANIZATION (ILO). World day for safety and health at work: a background paper. Geneva: International Labour Office, 2005.

JABLONOWSKI, Nicolai Davi; SCHAFFER, Andreas; BUREAUL, PETER. Still present after all these year: persistence plus potential toxicity raise questions about the use of atrazine. Environmental Science and Pollution Research International, v. 18, n. 2, p. 328-331, Feb. 2011.

LEITE, José Rubens Morato; AYALA, Patryck. Direito ambiental na sociedade de risco. Rio de Janeiro: Forense Universitária: 2004.

LONDRES, Flávia. Agrotóxicos no Brasil: um guia para ação em defesa da vida. Rio de Janeiro: AS-PTA - Assessoria e Serviços a Projetos em Agricultura Alternativa, 2011.

LUCCHESI, Geraldo. Agrotóxicos: a construção da legislação. Estudo, set. 2005. Disponível em: <http://bd.camara.gov.br/bd/bitstream/handle/bdcamara/2227/agrotoxicos_construcao_ lucchese.pdf? sequence $=1>$. Acesso em: 28 nov. 2011. 
NODARI, Rubens Onofre. Risco à saúde dos seres vivos advindo dos agrotóxicos - ênfase nos herbicidas. In: ARAGAO, Alexandra. LEITE, José Rubens Morato; FERREIRA, Jovino dos Santos Ferreira; FERREIRA, Maria Leonor Paes Cavalcanti. Agrotóxicos: a nossa saúde e o meio ambiente em questão - aspectos técnicos, jurídicos e éticos. Florianópolis: Funjab, 2012.

PALMA, DCA. Agrotóxicos em leite humano de mães residentes em Lucas do Rio Verde - MT. Dissertação (Mestrado) - UFMT/ISC, Cuiabá, 2011.

PESTICIDE ACTION NETWORK EUROPE. NAP BEST PRACTICE. Sustainable use of pesticides. Implementing a National Action Plan. Disponível em: $<$ http://www.pan-europe. info/Resources/Reports/NAP_best_practice.pdf>. Acesso em: 21 fev. 2013.

PIMENTEL, David. Amounts of pesticides reaching target pests: environmental impacts and ethics. Journal of Agricultural and Environmental Ethics, v. 8, n. 1, p. 17-29, 1995.

PIRES, Dario Xavier Pires; CALDAS, Eloísa Dutra Caldas; RECENA, Maria Celina Piazza. Uso de agrotóxicos e suicídios no Estado do Mato Grosso do Sul, Brasil. Disponível em: <http:// www.scielosp.org/scielo.php?pid=S0102-311X2005000200027\&script=sci_arttext $>$. Acesso em: 09 jun. 2012.

PRETTY, Jules; GUIJT, Irene; SCOONES, Ian; THOMPSON, John. Regenerating Agroecology of low-external input and community-based development. In: KIRKBY, John; O'KEEFE, Phil; TIMBERLAKE, Lloyd (Eds.). The earthscan reader in sustainable development. UK, 1999.

; WAIBEL, Herrmann. Paying the price: the full cost of pesticides. In: PRETTY, J. (Ed.). The pesticide detox. London: Earthscan, 2005.

RIO VERDE AGORA. Alunos de escola atingida por agrotóxicos passam bem. 3 maio 2013. Disponível em: <http://www.rioverdeagora.com.br/noticias/cidade/alunos-de-escola-ruralatingida-por-agrotoxico-passam-bem>. Acesso em: 08 maio 2013.

SADELEER, Nicolas. Environmental principles. From political slogans to legal rules. Oxford; New York: Oxford University Press, 2008.

SANBORN, M; COLE, D; KERR, K; VAKIL, C; SANIN; LH; BASSIL, K. Pesticides literature review: Systematic review of pesticide human health effects. Toronto: The Ontario College of Family Physicians, 2004. Disponível em: <http://www.ocfp.on.ca/docs/public-policydocuments/pesticides-literature-review.pdf?Status=Master>. Acesso em: 20 jan. 2012.

SARLET, Ingo Wolfgang; FENSTERSEIFER, Tiago. Notas sobre a proibição de retrocesso em matéria (socio) ambiental. In: O PRINCÍPIO da proibição de retrocesso ambiental. Brasília: Senado Federal, 2011.

SNEDEKER, Suzanne M. Precautionary Pesticide Selection. American Nurseryman, v. 203, n. 3, 2006. 
SOARES, Wagner Lopes. Uso dos agrotóxicos e seus impactos à saúde e ao ambiente: uma avaliação integrada entre a economia, a saúde pública, a ecologia e a agricultura. Tese (Doutorado) - Programa de Pós-Graduação da Escola Nacional de Saúde Pública Sergio Arouca. Rio de Janeiro, 2010.

; PORTO, Marcelo Firpo. Atividade agrícola e externalidade ambiental: uma análise a partir do uso de agrotóxico no cerrado brasileiro. Ciên. Saúde Coletiva, Rio de Janeiro, v. 12, n. 1, jan./mar. 2007.

SUNSTEIN, Cass R. Risk and reason. Safety, Law and the Environment. Cambridge, Mass.: Cambridge University Press, 2002.

THRUPP, Lori Ann. Inappropriate incentives for pesticide use: agricultural credit requirements in developing countries. Agriculture and Human Values, v. 7, n. 3/4, p. 62-69, 1990.

TRIBUNAL CENTROAMERICANO DEL AGUA. Caso: Fumigación aérea en finca Carrandi, Matina, Província de Limón. Marco Machore versus Standard Fruit Company, Ministerio de Obras Públicas y Transportes; Dirección General de Aviación Civil; Ministerio da Agricultura y Ganadería. Veredictos Segunda Audiencia Pública Llevada a cabo del 15 a 19 de marzo de 2004. San José, Costa Rica. Disponível em: <http://tragua.com/wp-content/uploads/2012/04/ veredicto_finca_carrandi.pdf $>$. Acesso em: 04 abr. 2013.

UNITED NATIONS ENVIRONMENT PROGRAMME (UNEP). Urgent Action Needed to Reduce Growing Health and Environmental Hazards from Chemicals: UN Report. 5 Set. 2012. Disponível em: $<$ http://www.unep.org/newscentre/Default.aspx?DocumentID=2694\&Articl $\mathrm{eID}=9266 \& \mathrm{l}=\mathrm{en}>$. Acesso em: 10 out. 2012.

WARGO, John. Our children's toxic legacy. How science and law fail to protect us from pesticides? 2. ed. New Haven: Yale University Press, 1998.

WORLD HEALTH ORGANIZATION REGIONAL OFFICE FOR EUROPE AND EUROPEAN ENVIRONMENT AGENCY. Children's health and environment: a review of evidence. Luxembourg: European Environment Agency Series, 2002.

Maria Leonor Paes Cavalcanti Ferreira - Pós-Doutoranda em Direito pela Universidade Federal de Santa Catarina. Professora do Centro de Ensino Superior de Santa Catarina. Diretora de Comunicação do Instituto O Direito por um Planeta Verde. Florianópolis/SC, Brasil.E-mail: marialeonorf@hotmail.com. 